\title{
EMERGING CLOUD COMPUTING PARADIGM: VISION, RESEARCH CHALLENGES AND DEVELOPMENT TRENDS
}

\author{
Kunal Sharma ${ }^{1}$, Susheel Thakur ${ }^{2}$, Arvind Kalia ${ }^{3}$, Jawahar Thakur ${ }^{4}$, Sunil Kumar ${ }^{5}$ \\ ${ }^{I}$ Student B.Tech (I.T), UIIT, Himachal Pradesh University, H.P, India \\ ${ }^{2}$ Student M.Tech (CS), Dept. of Computer Science, Himachal Pradesh University, H.P, India \\ ${ }^{3}$ Professor, Dept. of Computer Science, Himachal Pradesh University, H.P, India \\ ${ }^{4}$ Associate Professor, Dept. of Computer Science, Himachal Pradesh University, H.P, India \\ ${ }^{5}$ Programmer, UIIT, Himachal Pradesh University, H.P, India
}

\begin{abstract}
Cloud computing has recently emerged as a new paradigm for hosting and delivering utility-oriented IT services to users over the Internet. Cloud computing is lucrative to enterprise owners as it eliminates the requirement for users to plan ahead for resource provisioning, allows organization to initiate from the small and increase resources only when there is a hike in service demand. Cloud computing has emerged as a new technology that will lead the next generation of Internet. It tries to provide optimal and efficient computing through collaboration, agility, availability and scalability. In this paper, the cloud computing paradigm is illustrated in a variety of aspects and certain open challenges of research and recent development trends are being discussed. The aim of this research paper is to provide a comprehensive overview of the cloud computing paradigm, identify its major research challenges and recent development trends taking place in this increasingly important field.
\end{abstract}

Keywords: Mobile Cloud Computing, Live migration, Utility Computing, Virtualization.

\section{INTRODUCTION}

In last few decades, there has been rapid development in ICT (Information and Communication Technology) especially in processing, storage, and Internet technologies. The technologies such as parallel computing, distributed computing, grid computing and now, the cloud computing, have their main focus at allowing access to computational engines or computing resources by dynamic resource provisioning in fully virtualized manner. Basically these technologies are aiming at offering computing as utility; Utility Computing is on-demand delivery of computing power ("pay-as-you-go-on"), likewise as traditional public utility services.

Cloud Computing is offering utility-oriented IT services to users worldwide. Based on a pay-as you-go model, it enables hosting of numerous applications from consumer, scientific and business domains. In 1969, Leonard Kleinrock [12], one of the chief scientists of the original Advanced Research Projects Agency Network (ARPANET) which seeded the Internet, said: "As of now, computer networks are still in their infancy, but as they grow up and become sophisticated, we will probably see the spread of computer utilities "which, like present electric and telephone utilities, will service individual homes and offices across the country." This vision of computing utilities based on a service provisioning model anticipated the massive transformation of the entire computing industry in the $21 \mathrm{st}$ century whereby computing services will be readily available on demand, like other utility services available in today's society [17]. The factors that led to the development and occurring of cloud computing involves: development of grid computing, the high quality storage technology, data transportation, and Web 2.0, especially the development of virtualization [5].

Cloud Computing is merging of distinct technologies like resource pooling, virtualization, dynamic provisioning, utility computing, on-demand deployment of resources, Internet delivery of services to deploy and scale applications for businesses and individuals. The remainder of this paper is organized as follows. In section 2 an overview of the cloud computing paradigm has been provided. Section 3 discusses the evolution of the cloud computing technology over the period of time. Section 4 and 5 focuses on the cloud computing service, deployment models and service level agreements (SLA). Section 6 discusses the key design challenges in the cloud computing paradigm. Section 7 and 8 provides the fundamental insights into the recent development trends of Cloud computing and conclusion of the paper.

\section{CLOUD COMPUTING}

With the rapid development in the processing, storage technologies and the success of the internet, computing resources have become reasonable, powerful and globally available than ever before. Personnel in businesses are trying to find out methods to cut costs while maintaining the same performance standards. Their aspirations to grow have led them to try new ideas and methods even under the peer pressure of limiting computing resources. This realization has enabled the actualization of a new model for computing called cloud computing, in which the resources (e.g. cpu, network, etc.) are provided through the internet to user as 
general utilities in a pay-as-you-go and on-demand basis [18]. According to the U.S. Government's National Institute of Standards and Technology (NIST), Cloud Computing is "a model for enabling convenient, on-demand network access to shared pool of configurable computing resources (e.g. network, servers, storage, applications, and services) that can be rapidly provisioned and released with minimal management effect or service provider's interaction [15]. The cloud computing model resources (e.g. networks, storage, and services) as general utilities are provisioned so that they can be leased or released by users over the Internet in an on-demand manner.

Cloud computing can also be defined as 'Cloud computing is Internet-based computing, whereby shared resources, software's, and information are provided to end users on demand, like the electricity grid. Conceptually, it is a paradigm shift where background details are abstracted from users, who no longer need knowledge of, expertise in, or control over the technology infrastructure "in the cloud" that supports them. Cloud computing describes a new supplement, consumption, and delivery model for IT services based on Internet, and it typically involves the provision of dynamically scalable and often virtualized resources as a service over the Internet' [5]. The main reason for the various views and perceptions of cloud computing is that unlike other technological terms, this is not a new technology, but rather a new technology model that offers a new approach for running businesses.

\section{EVOLUTION OF CLOUD COMPUTING}

In the 1960s, John McCarthy envisioned that computing facilities will be provided to the general public like a utility [6].In 1990s, the term 'cloud' was used to describe large ATM networks. But 'Cloud Computing', started gaining popularity after Eric Emerson Schmidt, CEO Google used this word to describe business model for providing services across the Internet 2006.

The evolution process of cloud computing went through: networking, network-sharing, information sharing, resource sharing and service sharing.

It can be clearly stated that cloud computing has evolved in stages from since last few years. Cloud computing leverages the existing technologies to meet out the technological and economic requirements of today's demand for information technology. Cloud computing is often compared to following technologies, each of which shares certain aspects with cloud computing.

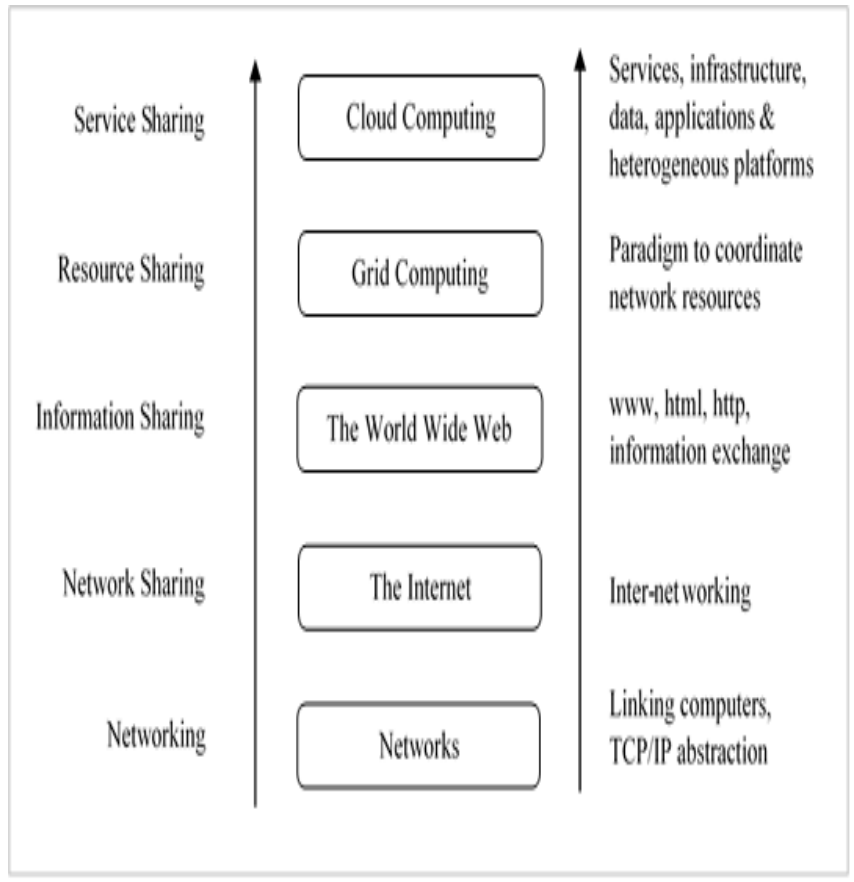

Fig -1: Cloud computing evolution since networks

Grid Computing: Grid computing is the collection of computer resources from multiple locations to reach a common goal. The grid can be thought of as a distributed system with non-interactive workloads that involve a large number of files". Grids are a form of distributed computing whereby a "super virtual computer" is composed of many networked loosely coupled computers acting together to perform large tasks. Cloud computing adds various other technologies (e.g. Virtualization, Server Consolidation, Security) to Grids to enhance the working environment [10].

Utility Computing: Utility computing offers various computing resources, such as networks, storage, processing to end users as metered services on the basis of 'pay-as-yougo' model. Cloud computing is a big picture of utility computing as it adopts the features of utility computing with 'pay-as-you-go' model, automated resource provisioning at maximum resource utilization and minimum operating cost.

Virtualization: Virtualization abstracts the low-level details of the hardware and other physical resources to offer an easy virtualized environment for the application levels. Virtualization Technology enables the decoupling of the application payload from the underlying physical hardware and provides virtualized resources for higher level applications [18]. For cloud computing, virtualization is the main component as virtualized resources from the pool of physical resources can be provisioned on-demand basis in a real-time scenario.

Autonomic Computing: Autonomic computing refers to the self-managing characteristics of distributed computing resources, adapting to unpredictable changes while hiding intrinsic complexity to operators and users. Started by IBM in 2001, this initiative ultimately aims to develop computer systems capable of self-management, to overcome the rapidly growing complexity of computing systems 
management, and to reduce the barrier that complexity poses to further growth [2]. Cloud computing adopt the features of autonomic computing too.

This is a clear indication that cloud has evolved over a period of time with advancements in its neighboring technology. Cloud computing leverages virtualization technology to achieve the goal of providing computing resources as a utility. Cloud computing paradigm shares certain aspects with grid computing and autonomic computing but differs from them on other aspects. Therefore, it offers unique benefits and imposes distinctive challenges to meet out its requirements. The features that make cloud highly interesting to businesses are:

No initial investment on infrastructure or resources: Pay-as-you-go pricing model offers the business owners a freedom to start gaining benefits from cloud without making an initial investment on infrastructure. Simply lease the resources from cloud according to needs, pay for the usage and release the resources when they are not required.

Low infrastructure operational cost: As resources are allocated and de-allocated on-demand basis, thus a cloud user no-longer need resources to be permanently installed in order to meet peak load requirements. And this saves a huge on operational costs.

Scalability: The need of resources of an Internet application varies over time. And this varying need imposes a threat over efficient utilization of resources. But with cloud, applications can be scaled-up and scaled-down as per requirements of the end user.

Ease in access: As cloud providers need to provide infrastructure or platform as services to the end users, they are supposed to offer a management console through which cloud users can manage their services over Internet through the use of web-browsers, phones, and PDAs. Cloud computing paradigm offers such capabilities.

Reduced risks and expenses: The end users who are going to use innovation and services shift their infrastructure risks to the cloud providers, thus they are no longer responsible for such risks managements and expenses where hardware might fail.

\section{CLOUD MODEL}

According the definition given by NIST, the cloud model is composed of five essential characteristics, three service models, and four deployment models.

The five essential characteristics of cloud are: on-demand self-service, broad network access, resource pooling, rapid elasticity, measured service. The computing resources such as servers, storage can be leased or released on-demand without any human interaction with the cloud service providers over the Internet using heterogeneous devices like desktops, laptops and mobiles phones. However, the service providers provisioned their resources which are shared by multiple users by the concept of virtualization of physical resources. The cloud consumers is charged according to their rapid elastic demands and for the services as per their resource usage using appropriate metrics such as storage usage, CPU hours, and bandwidth usage.

\subsection{Cloud Service Models}

The three Cloud service models are: Software as a Service (SaaS), Infrastructure as a Service (IaaS) and Platform as Service (PaaS).

\subsubsection{Software as a Service (SaaS)}

SaaS allows consumers to use software or applications that run on the cloud infrastructure, simply making the use of web-browsers. Consumers don't have any control or the access to the cloud infrastructure which hosts the respective software or application. In this model, the provider takes care of all software development, maintenance, and upgrades. Saas is now becoming an accepted model of delivery for application like accounting, CRM, ERP, HRM etc..

Salesforce is the leader in SaaS computing and is best known for its on-demand Customer Relationship Management solution. The pricing model [19] in SaaS bills its clients in the following three ways: Pay-per-user, unlimited-usage-fixed-cost, and pay-as-you-go. In pay-peruser strategy, a separate cost is incurred for each user of a SaaS application, periodically (usually monthly), for the number of registered users. This pricing model is further extended to pay-per-multiple-user pricing model, in which cost is incurred for a specified number of users.

Unlimited-usage-fixed-cost billing model is usually accepted by the client organization because this pricing model is easy to understand and with this model clients can easily predict their ongoing software expenses, and their monthly bills, since for unlimited number of users, their monthly bills remains nearly same from one billing cycle to the next. However, in pay-as-you-go model, the consumers will be charged for the number of users and the amount of resources consumed over a given period of time.

\subsubsection{Infrastructure as a Service (IaaS)}

Infrastructure as a service model of cloud computing is a low level layer of abstraction that allows the consumers to access cloud infrastructure. This model offers hardware, software, and equipments through the use of virtual machines with a resource usage based pricing model to deliver software application development environments. 


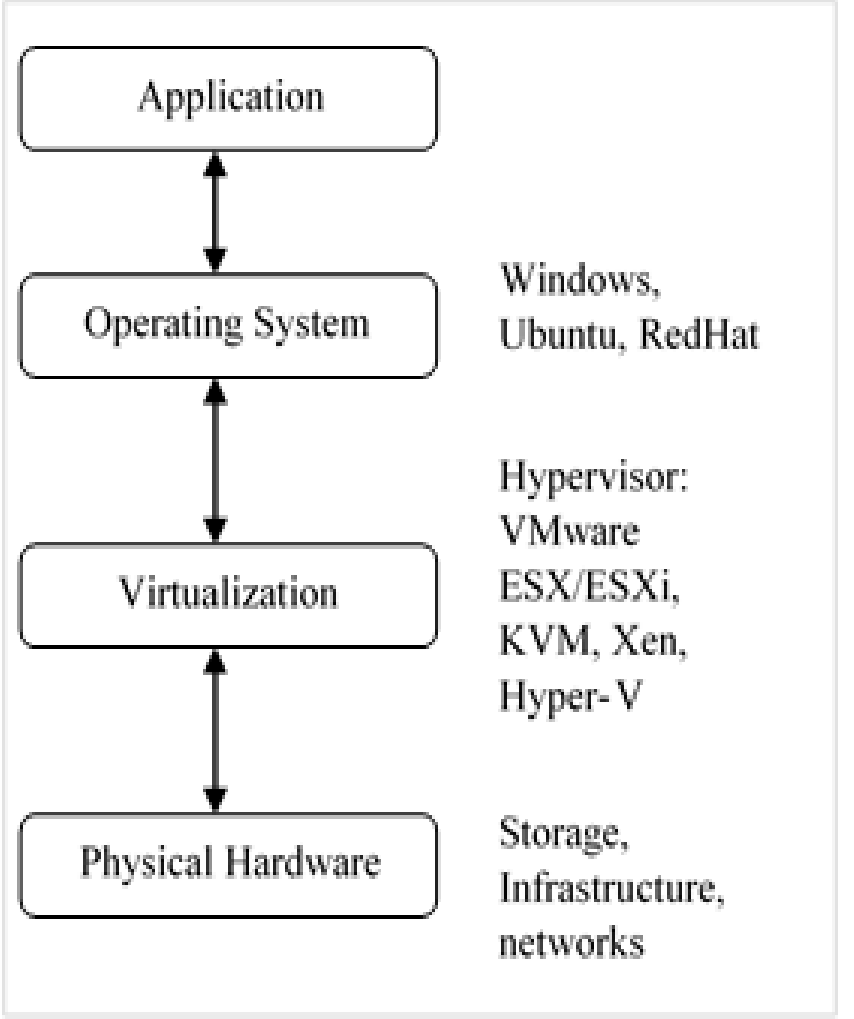

Fig -2: Layers in IaaS cloud

A programmer should be able to consider IaaS as a flexible, standard and virtualized operating environment that can become foundation for PaaS and SaaS. Simply, it is the responsibility of the provider to control and manage configurations and operations of operating system, software, and database being lended. The Amazon Elastic Compute Cloud (EC2) and Simple Storage Service (S3) are popular examples of IaaS.

The pricing model is again per-per-use. The pricing for EC2 is done as the basis of clock hours of service time (e.g. from the time Amazon EC2 instances are launched until they are terminated, or from the time elastic IPs are allocated until they are de-allocated, i.e. charging for running resources only), machine configuration (i.e. the physical capacity of Amazon EC2 instance you choose, and the instance characteristics may vary with OS, number of cores, memory, and load storage), number of instances and machine purchase type [1].

Table -1: Comparison between cloud service models

\begin{tabular}{|l|l|l|l|l|}
\hline Type & $\begin{array}{l}\text { Cons } \\
\text { umer }\end{array}$ & $\begin{array}{l}\text { Services } \\
\text { provided by } \\
\text { cloud }\end{array}$ & $\begin{array}{l}\text { Service } \\
\text { level } \\
\text { coverage }\end{array}$ & $\begin{array}{l}\text { Customiza } \\
\text { tion }\end{array}$ \\
\hline SaaS & $\begin{array}{l}\text { End } \\
\text { User }\end{array}$ & $\begin{array}{l}\text { Finished } \\
\text { Applications }\end{array}$ & $\begin{array}{l}\bullet \text { A } \\
\text { pplicatio } \\
\text { n Uptime } \\
\bullet \begin{array}{l}\bullet \\
\text { pplicatio A } \\
\text { n } \\
\text { coverage }\end{array}\end{array}$ & $\begin{array}{l}\text { M } \\
\text { inimal to } \\
\text { customizati } \\
\text { on } \\
\text { apabilities } \\
\text { dictated by } \\
\text { market or } \\
\text { provider }\end{array}$ \\
\hline
\end{tabular}

\begin{tabular}{|c|c|c|c|c|}
\hline PaaS & $\begin{array}{l}\text { Appli } \\
\text { cation } \\
\text { owner }\end{array}$ & $\begin{array}{l}\text { - } \quad \mathrm{Ru} \\
\text { ntime } \\
\text { environment } \\
\text { for } \\
\text { application } \\
\text { code } \\
\text { - Clo } \\
\text { ud storage } \\
\text { - Oth } \\
\text { er cloud } \\
\text { services } \\
\text { such as } \\
\text { integration }\end{array}$ & $\begin{array}{l}\bullet \quad E \\
\text { nvironme } \\
\text { nt } \\
\text { availabili } \\
\text { ty } \\
\text { nvironme } \\
\text { nt } \\
\text { performa } \\
\text { nce } \\
\text { - } \\
\text { o } \\
\text { applicatio } \\
\text { n } \\
\text { coverage }\end{array}$ & $\begin{array}{l}\text { - Hi } \\
\text { gh degree } \\
\text { of } \\
\text { application } \\
\text { level } \\
\text { customizati } \\
\text { on } \\
\text { available } \\
\text { within } \\
\text { constraints } \\
\text { of the } \\
\text { service } \\
\text { offered } \\
\text { - } \\
\text { any } \\
\text { application } \\
\text { will need } \\
\text { to be } \\
\text { rewritten }\end{array}$ \\
\hline IaaS & $\begin{array}{l}\text { Appli } \\
\text { cation } \\
\text { owner } \\
\text { or IT } \\
\text { provi } \\
\text { des } \\
\text { Os, } \\
\text { middl } \\
\text { eware } \\
\text { and } \\
\text { applic } \\
\text { ation } \\
\text { suppo } \\
\text { rt }\end{array}$ & $\begin{array}{lc}\bullet & \text { Virt } \\
\text { ual Server } \\
\bullet \quad \text { Clo } \\
\text { ud Storage }\end{array}$ & $\begin{array}{l}\text { - } \\
\text { irtual } \\
\text { server } \\
\text { availabili } \\
\text { ty } \\
\bullet \quad \mathrm{T} \\
\text { ime to } \\
\text { provision } \\
\bullet \quad \mathrm{N} \\
\text { o } \\
\text { platform } \\
\text { or } \\
\text { applicatio } \\
\mathrm{n} \\
\text { coverage }\end{array}$ & $\begin{array}{l}\text { - M } \\
\text { inimal } \\
\text { constraints } \\
\text { on } \\
\text { application } \\
\text { s installed } \\
\text { on } \\
\text { standardize } \\
d \text { virtual } \\
\text { OS builds }\end{array}$ \\
\hline
\end{tabular}

\subsubsection{Platform as a Service (PaaS)}

According to programmer's view, Cloud computing paradigm enables them to design, build, test, deploy, and update applications with a couple of his friends on weekends, over a set of programming languages, tools and application development platforms. With platform as a service, the programmers or software engineers can develop their applications and transfer them to servers and users over the Internet.

Google App Engine and Microsoft Azure Cloud Services are great examples of PaaS. Applications need middle ware such as databases, operating systems, runtime environments, web servers, application servers, and other components to run; and with PaaS, software developers can focus on development and functionality of their software as opposed to manage middleware, and the dynamic demand of infrastructure. PaaS is playing key role in SaaS. 


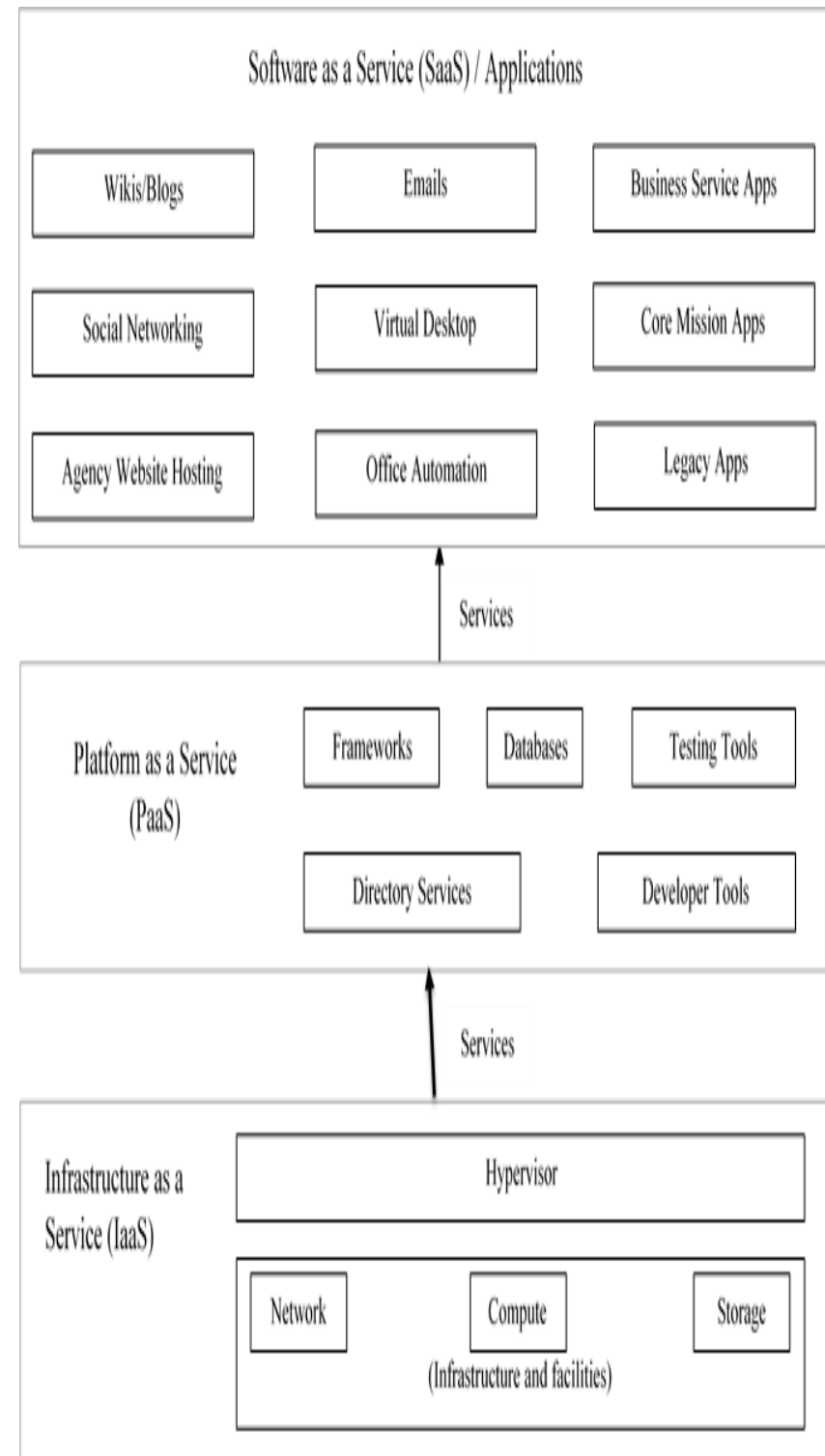

Fig -3: An abstract view of cloud service models

The two main pricing models in PaaS are: pay-per-hour and pay-per-month. In case of Google App Engine, resources like instances are billed by the use per instance hour $(\$ 0.05$ per unit), outgoing network traffic is billed in GBs $(\$ 0.12$ per GB), Datastore Storage is billed in GBs per month (\$0.18 per GB) and so on [9].

\subsection{CLOUD DEPLOYMENT MODELS}

According to NIST, there are four deployment models in cloud computing: Private Cloud, Public Cloud, Community Cloud and Hybrid Cloud.

\subsubsection{Private Cloud}

Private Cloud is a cloud model in which all cloud infrastructures is architected and controlled by a particular or organization (on-premises and/or off-premises) within the respective firewall. A private cloud is a scalable cloud environment - providing the agility and efficiency of a public cloud - built on infrastructure dedicated exclusively for an organization. It can be hosted in an organization's own data center, in a partner data center, or at Rackspace. Private clouds are ideal when there is need to accelerate innovation, have large compute and storage requirements, or have very strict control, security and compliance needs [16]. A private cloud environment or infrastructure is ring fenced for the use of an organization at higher levels of network security. The resources are offered to private cloud from a specific pool of physical computers. The main features and benefits of private clouds are:

High security and privacy: a specific pool of physical resources with restricted access to connections made from behind one organization's firewall, on-site internal hosting and/or dedicated.

More control: as architected and controlled by a single organization.

High performance: as it is deployed inside the firewall on an organization's Intranet.

Customizable: the organization can customize hardware, network and storage performances, and

Cloud-Bursting: a service in which non-sensitive functions of a private cloud owner are switched over to a public cloud to free more space in a private cloud.

\subsubsection{Public Cloud}

This model is more recognizable to many consumers of cloud, under which a shared pool of physical resources is offered in a virtualized environment over the Internet.

The features offered by a public cloud model are: Ultimate Scalability (as vast pool of physical resources is available), cost-effectiveness, utility style costing (pay-as-you-go) model, reliability, flexibility, and location independence.

\subsubsection{Community Cloud}

A community cloud in computing is a collaborative effort in which infrastructure is shared between several organizations from a specific community with common concerns (security, compliance, jurisdiction, etc.), whether managed internally or by a third party and hosted internally and externally. The costs are spread over fewer users than a public cloud (but more than a private cloud), so only some of the cost savings potential of cloud computing are realized [5], [15].

\subsubsection{Hybrid Cloud}

This type of cloud uses the mix of three deployment models to meet the customer's requirements. For example, in practice, an enterprise can host its e-commerce site in a private cloud, and its brochure site in a public cloud. The concept of 'cloud bursting' comes into picture in the case of hybrid clouds. The benefits and features offered by a hybrid 
cloud configuration are: scalability, cost efficiency, flexibility, and security.

\section{SERVICE LEVEL AGREEMENT (SLA)}

SLA is a contract or agreement between the cloud service provider and consumer which commit and stipulate to provide majorly to a specified service level, fee, customer support and assistance, system performance levels, and penalty and enforcement provisions for services not offered. The QoS (Quality of Service), QoP (Quality of Protection), and responsibilities to both seller and buyer are fundamental grounds in SLA.

\section{OPEN RESEARCH CHALLENGES}

Despite of a great success and popularity of the cloud computing paradigm, the providers, developers, and consumers must consider issues, challenges or risks of cloud paradigm which includes user data privacy and security, service availability, performance, scalability, recovery, energy efficiency and programmability to take advantage of cloud computing. The research issues, challenges, or risks majorly includes: Automated Resource Provisioning, Server Consolidation, Virtualization and Virtual Machine Migrations, Security, and Software Development Frameworks.

\subsection{Automated Resource Provisioning}

How to feature cloud with on-demand lease and release of physical resources? How to provision resources in flash crowd effect? These questions addresses the challenges of QoS. The two commonly used approaches are: prediction, and reaction (reactive approach). In prediction approach, the application performance model is predicted at each particular level in terms of application instances; and based on the prediction model, the resources are allocated. However, in reaction or reactive approach of resource provisioning, resources are allocated and de-allocated immediately in accordance with demand fluctuations. And both these approaches impose necessities on this dynamic operating environment. The improvement in these approaches is a great research challenge so as to provision resources accurately as per needs.

\subsection{Server Consolidation}

How to maximize the resource utilization with minimum energy consumption?

According to Tony Iams [8], Managing VP, Stamford, CT USA, servers in many companies run at $15-20 \%$ of their capacity. And to cut unnecessary costs, and maximize return on investment (ROI), out of 518 respondents in a Gartner Group Research study $6 \%$ had conducted a server consolidation project, $61 \%$ were currently conducting one, and $28 \%$ were planning to do so in nearby future.

Server sprawl is a situation in which multiple underused servers take up more amount of computing, space and power, and thus consume more resources than can be justified by their workload. To prevent server sprawl, server consolidation focuses on the reduction of the number of physical resources used in cloud infrastructure by consolidating load using virtual technologies and enhancing their utilization. The virtualization technique of physical resources (e.g. Live VM migration) is often used to consolidate VMs residing on multiple underutilized servers on to a single server, so as to save energy. The server consolidation problem is often formulated with the vector bin-packing problem [3] which falls in the category of NP hard optimization problem.

Also the server consolidation (e.g. the communication among virtual machine) should not affect the application performance and servers must also be reactive to congestion.

\subsection{Virtual Machine Migration}

Virtualization technology enables the decoupling of the application payload from the underlying physical hardware and provides virtualized resources for higher level applications [18]. The technology also provides the ability to migrate virtual machines (VMs) between the physical systems and improves the response time, and reduces the number of physical systems.

Virtual Machine migration is the process of moving a virtual machine from one host or storage location to another [20]. Generally, a virtual machine running on a virtual server consists of a configuration file and one or more data files (virtual hard disk files, and other media files) [14]. Virtual machine migrations can be categorized to the following two main categories:

Cold Migration: A powered-off or suspended virtual machine is made to migrate from one host to another with or without movement of storage or data.

Hot or live migration: It refers to the process of moving a running virtual machine or application between different physical machines without disconnecting the client or application. Memory, storage, and network connectivity of virtual machines are transferred from the original host machines to the destination. When the down time of a VM during live migration is not noticeable by the end users, it is called as seamless live migration [13].

Xen and VMware have already implemented live migration of virtual machines. Clark et. al. [4] discovered the benefits of live migration of VM, migration of the entire OS and all its applications as a single unit from the process level migration approaches. The avoidance of hotspots is a major advantage of VM migration. The main research areas in VM migration are detection of migration and hotspots, so as to respond to sudden workload changes.

\subsection{Security}

Security is one of the major challenges to the growth of the cloud, and also the main reason for the slow acceptance of cloud computing paradigm by various organizations. 


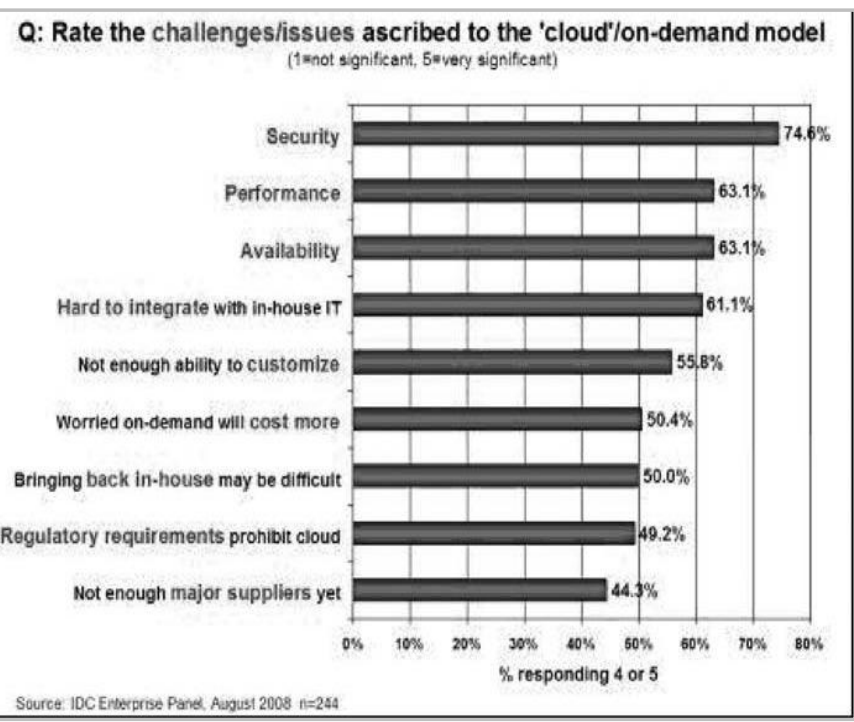

Fig -4: Results of IDC survey ranking security challenges, 2008 [7]

In accordance to Gartner 2008, the seven specific security issues that customers must raise with vendors before selecting a cloud vendor are: privileged user access, regulatory compliance, data location, data segregation, recovery, investigative support, and long term viability [11].

Ensuring secure data access and transfer, backup and recovery, auditing and certification over the multi-tenancy model and pooled resources are the great security challenges that require novel techniques to tackle with. Broadly speaking, storage security, middleware security, data security, network security, and application security, are major concerns for making cloud reliable via security.

\subsection{Software Frameworks}

The software programming techniques, languages, and frameworks are also keynotes for cloud providers because it is a layer where software application developers are going to work; and the applications thus developed over cloud can be of large scales and data intensive. Google App engine currently supports 4 programming languages including Python, Java, PHP, Go and a number of frameworks in each of these languages. Therefore, offering a managed environment for production of applications for several developer's expertise of different domains is a great challenge. MapReduce frameworks such as Hadoop for scalable and fault tolerant data processing is required by many organization nowadays, and tasks in Hadoop are either $\mathrm{I} / \mathrm{O}$ intensive or CPU intensive. Also, VMs with heterogeneous characteristics might be allocated to Hadoop nodes which further require operations to be optimized either for energy or performance.

\section{DEVELOPMENTS TRENDS}

Cloud computing has grown up in recent years and its major offerings include: IT infrastructure that can extend and contract, application or software development frameworks, application development and deployment techniques, management software to observe, monitor and setup cloud services, and networks that supports all of this. Cloud computing has initiated and accelerated a trend and environment in which individuals and organizations can easily innovate and experiment without having time and expense of setting, configuring, and deploying new physical hardware. But this is still an emerging area and it will be too soon to declare a victory. However, it is now a big business. In a report in Washington post, by the end of 2013 cloud computing market was estimated around $\$ 131$ billion, and expected to $\$ 207$ billion by 2016 .

Several key trends that can be identified in cloud computing paradigm are:

\subsection{Personal Cloud}

A report from Gartner Inc says that by the year 2014 [11], the personal cloud will replace the personal computer and in the new era users will be offered higher flexibility with devices they use for daily activities, to strengthen each device and bringing new level of user satisfaction and productivity.

In the current scenario, users that use smart phones, tablets, and various other mobile devices can save, connect, stream, and synchronize content over multiple platforms from different locations over the Internet.

\subsection{Cloud Service Management}

From the existing usage of cloud services by various companies, it is clear that most of companies have adopted a hybrid cloud deployment model which include private cloud, public cloud and traditional computing environment. And they are focusing on their planning for cloud services and management.

\subsection{Cloud Security}

In cloud computing paradigm, organizations shift their onpremises assets (data, processes or functions or applications) to cloud. And these assets are very important from the view point of every organization. These assets can be made public; cloud provider may access the assets; application or function can be changed by an outsider; the application may fail; the assets may be lost or unexpectedly change; and hence there is threat to the cloud with its security.

Data Security, Access, Transfer, Integrity, Segregation, Network Security, Authorization and Authentication, Application security, availability and backup are the major concerns in cloud security.

\subsection{Cloud Big Data}

For almost every company, data is growing at a fast rate and to manage and analyze this huge amount of data, technologies like Big Data are in demand. Cloud computing paradigm is now required to provide such technologies and frameworks to support this information and analytics which too at a faster pace. But as data will keep growing on cloud, 
its security and integrity is major concern for the cloud vendors. The security innovations are surely important for cloud vendors.

\subsection{Mobile Cloud Computing}

In Mobile Cloud Computing, both mobile networks and cloud computing have come together to bring benefits to users, network operators, cloud vendors and companies which offer their services through mobiles. Currently, a large number of applications including social media, and ecommerce is hosted over cloud and serviced for the mobiles using mobile applications and for web using web browsers. And this profits cloud vendors, network operators and also the companies.

Cloud computing is an emerging and trending paradigm, and many companies have moved to cloud, and many are planning.

\section{CONCLUSIONS}

Cloud Computing has emerged as rapidly developing paradigm for managing and delivering IT services over the Internet. The rise of cloud computing has led to changes in the landscape of information technology rapidly, and in turn fulfil the long-held promise of utility computing into reality. However, despite the major benefits offered by cloud computing, the current technologies are not so fully developed enough to realize its full potential. Many key challenges exists, including automatic resource provisioning, server consolidation and security management, are only starting to receive attention from the research community.

In this paper, we have surveyed the cloud computing paradigm from various aspects, and provides fundamental insights into the key technologies as well as research directions. As the development of cloud computing paradigm is still in infancy, for better understanding of the design challenges and recent development trends in cloud computing paradigm is being discussed, which will pave the way for further research in this area.

\section{REFERENCES}

[1]. Amazon Web Services and their pricing, How AWS pricing work, http://amazon.com/whitepapers/

[2]. Autonomic Computing, http://en.wikipedia.com/wiki/ Autonomic_computing

[3].Chandra Chekuri, Sanjeev Khanna, "On multidimensional packing problems", http://repository.upenn.edu/cgi/viewcontent.cgi?article $=108$ $0 \&$ context=cis_papers

[4]. Clark, C., Fraser, K., Hand, S., Hansen, J.G., Jul, E., Limpach, C., Pratt, I., Warfield, "A.: Live migration of virtual machines". in Proceedings of the 2nd Conference on Symposium on Networked Systems Design \& Implementation, Berkeley, CA, USA, USENIX Association, 2005.
[5]. Cloud Computing, http://en.wikipedia.com/wiki/Cloud _computing

[6]. D Parkhill, "The Challenges of Computer Utility", Addision-Wesley Reading, 1966

[7]. F. Gens., "New IDC IT Cloud Services Survey: Top Benefits and Challenges", IDC eXchange, Feb 2009, http://blogs.idc.com/ie/?p=730

[8]. Gartner Inc., Tony Iams, Analyst Profile Gartner, http://gartner.com/AnalystBiography?authorId=43654

[9]. Google App Engine Developers/Development and Pricing, http://developers.google.com/appengine/pricing/

[10]. Grid Computing, http://en.wikipedia.com/wiki/Grid _computing

[11]. Jon Brodkin, 'Gartner: Seven cloud computing security risks', http://www.infoworld.com/d/security-central/gartnerseven-cloud-computing-security-risks-853

[12]. L. Kleinrock, "A Vision for the Internet", ST Journal of Research, vol 2, issue 1 pp: 4-5, Nov, 2005.

[13]. Live Migration, Wikipedia, http://en.wikipedia.com/wiki/Live_migration

[14]. Microsoft and Virtual machine migration, Virtual Machine Migration Guide, http://technet.microsoft.com/

[15]. P. Mell and T Grance, "The NIST Definition of Cloud Computing", http://csrc.nist.gov/publications/nistpubs/800145/SP800-145.pdf

[16]. Rackspace the open cloud company, Rackspace Private Cloud, http://rackspace.com/cloud/private/

[17]. Susheel Thakur, Arvind Kalia, Jawahar Thakur, "Performance Analysis of Server Consolidation Algorithms in Virtualized Cloud Environment with Idle VMs", International Journal of Advance Research in Computer Science and Management Studies, vol 2, issue 3, March 2014.

[18]. Susheel Thakur, Arvind Kalia, Jawahar Thakur, "Performance Evaluation of Server Consolidation Algorithm in Virtualized Cloud Environment with Constant Load", International Journal of Advanced Research in Computer Science and Software Engineering, vol 4, issue 3, March 2014.

[19]. The Leader in Enterprise Platform as a Service (PaaS) | Apprenda, http://apprenda.com/library/software-ondemand/sas-billing-pricing-models/

[20]. VMware Publications, VMware vSphere 5.1 Documentation Center, http://pubs.vmware.com/vsphere51/index.jsp 